\title{
Composites Base on Geopolymer Matrices: Preliminary Fabrication, Mechanical Properties and Future Applications
}

\author{
T.D. Hung ${ }^{1, a}$, D. Pernica ${ }^{1, b}$, D. Kroisová ${ }^{1, c}$, O. Bortnovsky ${ }^{2, d}$, \\ P. Louda ${ }^{1, e}$ and V. Rylichova ${ }^{1, f}$ \\ ${ }^{1}$ Department of Material Science, Faculty of Mechanical Engineering, \\ Technical University of Liberec, Studentská 2, 46117 Liberec, Czech Republic \\ ${ }^{2}$ Research Institute of Inorganic Chemistry, Inc., Revoluční 84, 40001 \\ Ústí nad Labem, Czech Republic

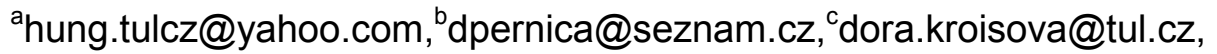 \\ doleg.bortnovsky@vuanch.cz, ${ }^{\mathrm{e}}$ petr.louda@tul.cz,'vladka.rylichova@tul.cz
}

\begin{abstract}
Keywords: Geopolymer, Geosynthesis, Geopolymerisation, Aluminosilicate, Thermoset, Autoclave, Impregnate, Saturate, Fiber reinforcement, SEM, lightweight, High strength, Fire resistant.
\end{abstract}

\begin{abstract}
Geopolymer matrice Composites are fabricated at room temperature or thermoset in a simple autoclave. After approximately four hours of curing, composite materials exhibit excellent properties. Finding applications of geopolymeric composites in all fields of industry are the hot topics. This paper covers: (i) mechanical properties of fibers: carbon, Saint-Gobain Cemfil/CFV alkali resistance glass (various types), ARG-NEC (Nippon electric Columbia) alkali resistance glass, Eglass for pultrusion, AR glass for pultrusion were evaluated in accordance with Japanese Industrial Standard (JIS R 7601). (ii) properties of geopolymeric matrices: geopolymeric matrices are fabricated from various types of geopolymeric resins that were made at Research Institute of Inorganic Chemistry, Inc., Czech Republic and testing for mechanical properties, and by SEM for structure characterization. (iii) fabrication procedures of geopolymer matrix composites with carbon and other fiber reinforcements. (iv) results of mechanical testing of geopolymer composites, SEM for adhesion between the matrix and reinforcement, and (v) Results and discussion.
\end{abstract}

\section{Introduction}

The remarkable achievements of inorganic chemistry made through geosynthesis and geopolymerisation include mineral polymers which termed as polysiatate or geopolymers, making us possible to fabricate composite materials not only with excellent mechanical properties such as lightweight and high strength but also with ideal fire resistant (can sustain temperatures up to $1250^{\circ} \mathrm{C}$ with long term exposure), non toxic fumes and smokes, and resisting all organic solvents (only affected by strong hydrochloric acid) [1-4]. These special properties permit us to use more efficiently geopolymer matrix composites in high technologies such as aerospace, naval architecture, ground transportation or automotive industry, especially for various applications that require high temperature resistance [5]. These materials can be replaced efficiently lightweight high strength composites which are made with carbon or glass fibers and organic matrices or ceramic matrices (high costs associated with special processing requirements and most organic matrix composites cannot be used in applications that require more than $200^{\circ} \mathrm{C}$ temperature exposure) $[5,6]$. Moreover composites base on Geopolymeric matrices are handled easily and do not require high heat, they are almost fabricated at room temperature or thermoset in a simple autoclave (usually less than $150^{\circ} \mathrm{C}$ ). After approximately four hours composite materials are produced. In addition, most of types of fibers can be used with the geopolymer matrices and they can protect carbon from oxidation [5]. Due to the outstanding advantages more and more public and private research institutes and companies are investigating and finding applications in all fields of industry, such as civil engineering, plastics industries, waste management, automotive and aerospace industries, non ferrous foundries and metallurgy, etc $[1,3,4]$. 


\section{Experimental}

Mechanical properties of filaments: Single filament of each kind of fibers was separated with a magnifier, prepared was evaluated in accordance with Japanese Industrial Standard (JIS R 7601) [7].

Geopolymer matrices: The geopolymeric resins were left in the molds for 24 hours at laboratory temperature $\left(20^{\circ} \mathrm{C}\right)$ and then placed in a furnace for curing at $80^{\circ} \mathrm{C}$ for 10 hours. Finally, they were dried at $80^{\circ} \mathrm{C}$ for 10 hours in an oven. The samples were made with the dimentions and tested under three-point bending in accordance with ASTM D790(3), and SEM (Scanning Electron Microscope) method was used to analyse the structure of geopolymers.

\section{Composite base on geopolymer}

- The continuous fibers were impregnated or saturated with the resin mixture ("wet-out") in the resin impregnator by the assisting of "impregnation machine" (Fig.1);

- Saturated fibers were set into silicon molds layer by layer.

- The samples were cured under a technique called "press vacuum bagging"(-1atm and room temperature $20^{\circ} \mathrm{C}$ ) for 2 hours and then under a technique called "hot press vacuum bagging" (-1 atm in the furnace at $85^{\circ} \mathrm{C}$ ) for 5 hours.

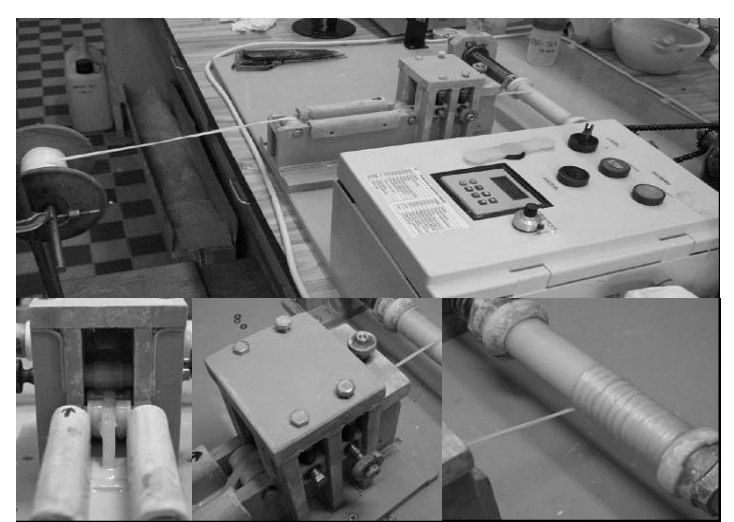

Fig. 1 Impregnation machine

- The samples then were dried in the oven at $80^{\circ} \mathrm{C}$ for 15 hours.

During the preparing and curing process the samples were weighted to calculate the percentage of fibers in impregnated, uncured, cured and dried composites (per weight). The sample dimentions were made and tested under three-point bending in accordance with ASTM D790(3) and SEM for studying of the adhesion or interaction between fibers and geopolymeric matrices.

\section{Results and Discussion}

Table 1. Mechanical properties of Filaments

\begin{tabular}{|l|c|c|c|c|c|c|}
\hline \multicolumn{1}{|c|}{ Type of fiber } & $\begin{array}{c}\text { Average } \\
\text { diameter }[\mu \mathrm{m}]\end{array}$ & $\begin{array}{c}\text { No. of filaments } \\
\text { in a bundle }\end{array}$ & $\begin{array}{c}\mathrm{F}_{\max } \\
{[\mathrm{N}]}\end{array}$ & $\mathrm{A}[\%]$ & $\begin{array}{c}\sigma_{\max } \\
{\left[\mathrm{N} / \mathrm{mm}^{2}\right]}\end{array}$ & $\begin{array}{c}\mathrm{E} \\
{\left[\mathrm{N} / \mathrm{mm}^{2}\right]}\end{array}$ \\
\hline C12-1200 tex & 7.00 & 12000 & 0.20 & 0.65 & 5286.19 & 443714 \\
\hline C24-1600 tex & 6.92 & 24000 & 0.20 & 1.08 & 5379.56 & 404302 \\
\hline CFV-2450 tex & 16.00 & $4500-5000$ & 0.40 & 2.20 & 1997.55 & 92530 \\
\hline ARG-2500 tex & 14.00 & $4000-5000$ & 0.23 & 1.95 & 1494.86 & 75777 \\
\hline E-glass 2400 tex & 24.00 & $1900-2000$ & 0.68 & 2.81 & 1492.83 & 58479 \\
\hline CemFil-2450 tex & 14.00 & $4500-5000$ & 0.38 & 2.21 & 2456.78 & 112995 \\
\hline AR-2400 tex & 27.00 & $1600-1700$ & 0.86 & 2.65 & 1506.29 & 58325 \\
\hline
\end{tabular}

Table 2. Mechanical properties of geopolymer matrices

\begin{tabular}{|l|c|c|l|c|c|}
\hline $\begin{array}{c}\text { Name of } \\
\text { Geopolymer }\end{array}$ & $\sigma_{\max }[\mathrm{MPa}$ & $\mathrm{E}[\mathrm{MPa}]$ & $\begin{array}{c}\text { Name of } \\
\text { Geopolymer }\end{array}$ & $\sigma_{\max }[\mathrm{Mpa}]$ & $\mathrm{E}[\mathrm{MPa}]$ \\
\hline MK 125 & 9.86 & 3500 & Q3V-28 & 26.2 & 5800 \\
\hline MK-D 1,6 & 10.26 & 5000 & Q3V-24 & 29.7 & 9660 \\
\hline HD 1,6 108/40 & 9.40 & 3950 & Q3V-23 & 22.8 & 7500 \\
\hline HD 2,0 108/40 & 11.96 & 5562 & Q3V-30 & 22.3 & 4700 \\
\hline H 110 108/40 & 10.80 & 4715 & Q3V-21 & 22.2 & 9930 \\
\hline H 110 & 16.65 & 10675 & Q3V-22 & 30.3 & 4600 \\
\hline H 160 & 13.60 & 8286 & Q3V-32 & 16.4 & 5470 \\
\hline IRk-3 & 10.9 & 4150 & Q3V-31 & 51.0 & 8630 \\
\hline
\end{tabular}


Table 3. Mechanical properties of geopolymer matrix composites in flexural testing

\begin{tabular}{|l|c|c|c|c|c|c|}
\hline \multicolumn{1}{|c|}{ Name of Geopolymer } & $\begin{array}{c}\sigma_{\max } \\
{[\mathrm{MPa}]}\end{array}$ & $\mathrm{s}$ & $\begin{array}{c}\mathrm{V} \\
{[\%]}\end{array}$ & $\begin{array}{c}\mathrm{E} \\
{[\mathrm{MPa}]}\end{array}$ & $\mathrm{s}$ & $\begin{array}{c}\mathrm{V} \\
{[\%]}\end{array}$ \\
\hline Q3V-30 AR 2400 tex & 166.8 & 21.4 & 12.8 & 17500 & 4500 & 25.8 \\
\hline Q3V-30 C 1600 tex-press & 160.3 & 10.8 & 6.7 & 26800 & 2600 & 9.7 \\
\hline Q3V-30 C 1600 tex & 146.3 & 52.4 & 35.8 & 17400 & 8000 & 45.9 \\
\hline IRk-3 C 1600 tex & 199.1 & 26.6 & 13.4 & 26300 & 3700 & 14.0 \\
\hline IRk-3 AR 2400 tex & 106.4 & 5.1 & 4.8 & 16590 & 1660 & 10.0 \\
\hline BL 160 AR 2400 tex-press & 95.1 & 14.8 & 15.6 & 9400 & 3000 & 32.0 \\
\hline BL 160 AR 2400 tex & 130.1 & 29.5 & 22.7 & 11440 & 5400 & 47.3 \\
\hline Q3V 34 C 1600 tex-press & 159.3 & 8.9 & 5.6 & 25400 & 3660 & 14.4 \\
\hline Q3V 34 C 1600 tex & 135.1 & 59.2 & 43.8 & 16520 & 5130 & 31.0 \\
\hline Q3V 32b AR CemFil 2450 tex-press & 140.0 & 12.6 & 9.0 & 16150 & 6100 & 37.6 \\
\hline Q3V 32b AR CemFil 2450 tex & 146.4 & 50.8 & 34.7 & 14000 & 3813 & 27.2 \\
\hline Q3V 23a 10\% C 1600 tex & 203.1 & 64.7 & 31.9 & 18600 & 4400 & 23.6 \\
\hline Q3V 23a 10\% AR 2400 tex & 142.8 & 12.8 & 9.0 & 12400 & 2740 & 22.1 \\
\hline
\end{tabular}

Notes: $10 \%$ of epoxy water-soluble resin of geopolymeric resin was added (by weight).

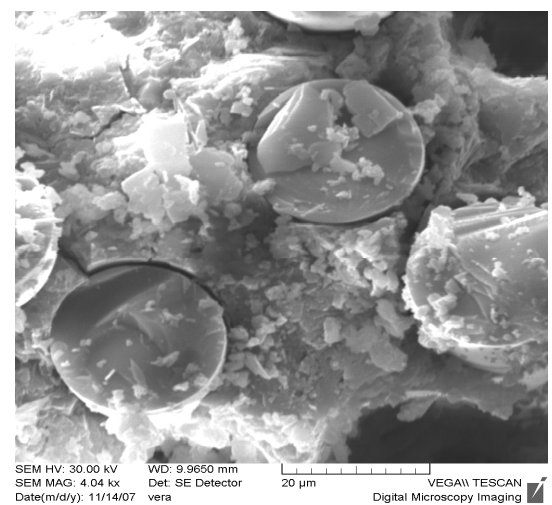

Fig. 2 SEM of $Q 3 V-30 A R$

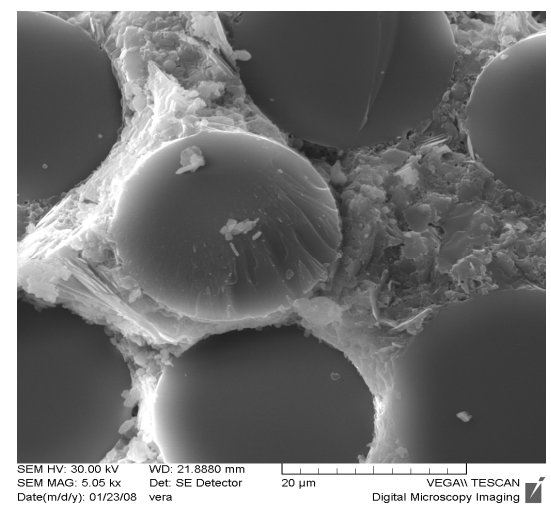

Fig. 3 SEM of $Q 3 V-23 E$

The Table 1 shows that among all types of fibers, carbon fiber $(\mathrm{C} 12, \mathrm{C} 24)$ provides the highest strength, there is an insignificant difference between them $\left(\sigma_{\max }=5286 \mathrm{~N} / \mathrm{mm}^{2}\right.$ compares with 5379 $\mathrm{N} / \mathrm{mm}^{2}$ ), this value is about two times higher than for CFV glass fiber or Cemfil glass fibers and three times higher than the strength of ARG, AR and E glass fibers.

According to the strength of geopolymers we can divide into 2 groups, the group with Q3V abbreviation exhibits strength two times higher than the other geopolymer matrices (Table 2).

With the preliminary results in Table 3 we can recognize some interesting conclusions: Although strength of AR glass fiber itself is about three times lower than strength of carbon fiber but the strength of their composites with Q3V-30 geopolymeric matrix was almost the same. For all types of geoplymer matrices and fibers, the strength of composites increased when pressure was used during the curing process, excepting composites made from AR glass fiber and Cemfil glass fiber with BL160 and Q3V$32 \mathrm{~b}$ geopolmeric matrix respectively. In case of BL160-AR composite, it is due to short pot-life of BL160 geopolymeric resin at room temperature which affect of quality of prepared composites. In case of Q3V-32b Cemfil composites (where the influence of pressure is negligible) it is probably due to the properties of Cemfil glass roving, which consists of tens of separate strands each with 50-80 filaments in comparison with AR glass fiber roving, consists of thousands separate filaments.

In comparison with composites Q3V-30 AR glass (see Fig. 2) Figure 3 shows that the interaction between geopolymer matrix Q3V-23 and E glass fiber in their composite is very good. The good adhesion proposes the good mechanical properties of this composites material, however, this composite is brittle. It is probably due to poor alkali resistance of E-glass fiber in comparison with AR fiber types. Next investigations need to do to explain this behavior. 


\section{Summary}

Research and experiments are on going in Department of Material Science, Faculty of Mechanical Engineering, Technical University of Liberec, and Research Institute of Inorganic Chemistry, Inc., Ústí nad Labem, Czech Republic, which will permit us to find the additives for geopolymers, fabrication methods and curing conditions for geopolymer composites with the best adhesion between the reinforcements and geopolymer matrices. Finally we can receive the best properties of composite materials with relatively low cost for technological and industrial use in near future.

In order to apply geopolymer matrix composites to technological and industrial use, research and experiments are on going to carry out research on each special subject:

1. Effects of curing conditions on the adhesion or interaction between geopolymer matrices and reinforcements and mechanical properties of composites.

2. Abilities of non-fired, heat-resistant composite materials base on geopolymer matrices for thermal/heat insulation of high-temperature equipments.

3. Hybrid composites: glass fiber cores and lightweight geopolymer cores with carbon/glass fiber skins.

4. The degradation of carbon or glass reinforcements under alkali environment? And the effects of post curing (time, temperature and humidity...) on mechanical properties.

5. Comparison geopolymer composites with other composites (traditional lightweight refractory materials: $\mathrm{C} / \mathrm{C}$ composites, Ceramic matrix composites) in term of relative performance of polysialate composites, processing requirements, mechanical properties and environmental effects.

6. Environmental service performance (the ability to resist cracking, corrosion, thermal degradation, wear, and effects of foreign object impact damage)...

Acknowledgement: This work was supported by the Project FT-TA4/068.

\section{References}

[1] J. Davidovits: 30 Years of Successes and Failures in Geopolymer Applications - Market trends and Potential breakthroughs, Geopolymer 2002 Conference, Melbourne, Australia (2002).

[2] J. Davidovits: Geopolymer, Green Chemistry and Sustainable Development Solutions, Proceedings of the World Congress Geopolymer (2005), p. 9.

[3] L.M. Sheppard: Geopolymer composites: A ceramics Alternative to Polymer Matrices, the $105^{\text {th }}$ Annual Meeting and Explosition of the American Ceramic Society http://composite.about.com/library/weekly/aa030529.htm (2007).

[4] W.M. Kriven, M. Gordon and J.L. Bell: Microscopy and Microanalysis '04, (Proc. 62 ${ }^{\text {nd }}$ Annual Meeting of Microscopy Society of America) vol. 10 (2004), p. 404.

[5] C.G. Papakonstantinou and P.N. Balaguru: Geopolymer, Green Chemistry and Sustainable Development Solutions, Proceedings of the World Congress Geopolymer (2005), p. 201-208.

[6] C.G. Papakonstantinou and P.N. Balaguru, R.E Lyon: Elsevier - Composite Part B Vol. 32 (2001), p. 637-649.

[7] Translated and Published by Japanese Standards Association: JIS R 7601 - Japanese Industrial Standard - Testing Methods for Carbon Fibers (Japan, 1986).

[8] Information on http://www.geopolymer.org.

[9] Information on http://composite.about.com. 